\title{
Study on Longitudinal Stress of Urban Water Supply Network under the Action of Seismic Wave
}

\author{
Lijuan WANG \\ School of Civil Engineering and Transportation \\ Hebei University of Technology \\ Tianjin, China \\ e-mail: 2451813090@qq.com
}

Jiahui WANG

School of Civil Engineering and Transportation Hebei University of Technology

Tianjin, China

Butao JIANG

School of Civil Engineering and Transportation Hebei University of Technology

Tianjin, China

\author{
Xin LIU \\ School of Civil Engineering and Transportation \\ Hebei University of Technology \\ Tianjin, China \\ e-mail: 425288799@qq.com \\ Ying WANG \\ School of Civil Engineering and Transportation \\ Hebei University of Technology \\ Tianjin, China \\ Xiaoning LI \\ School of Civil Engineering and Transportation \\ Hebei University of Technology \\ Tianjin, China
}

\begin{abstract}
Based on the elastic foundation model and wave theory as well as fluid mechanics theory, considered of the influence of flow velocity in the pipe, vertical force of buried water supply pipeline are analyzed under the action of seismic wave. The bending moment and stress formula are derived, and the vertical stress calculation model of water supply pipeline under the action of seismic wave was established. The influence of different diameter, flow velocity, soil and earthquake intensity on the water supply pipeline is analyzed by numerical examples.
\end{abstract}

Keywords-water supply pipeline; seismic wave; stress; calculation model; flow velocity

\section{INTRODUCTION}

Urban water supply pipe network system is an important part of urban lifeline engineering system. It is easy to be damaged in the earthquake, even paralyzed and may subsequently lead to a variety of secondary disasters, directly affecting the life of people after the earthquake. China is a country with many earthquakes, but its water supply networks for seismic design start late and differ a lot compared with Japan, the United States and other developed countries. Most of the cities' water supply pipe network systems have not been a formal seismic design, and pipeline seismic analysis of the model is still not perfect. Especially water supply pipeline seismic analysis is not comprehensive enough.

Basing on the mutual deformation theory, the relative deformation theory of seismic wave was simplified as a sine wave. That is, fluctuating deformation of the soil is wrapped together with the deformation of the pipeline, under the action of earthquake wave. But due to the difference of the pipeline stiffness and soil stiffness, there is a relative sliding between the pipe and the surrounding soil, and the relative sliding will make the tube deformation smaller than the deformation of the soil. Based on the elastic foundation model and wave theory as well as fluid mechanics theory, considering the influence of flow velocity for the pipe and analyzing pipe stress when bent and filled with water.

\section{ANALYSIS OF VERTICAL DEFORMATION OF WATER SUPPLY PIPELINE UNDER THE ACTION OF EARTHQUAKE WAVES}

Longitudinal pipeline failure has been recognized as a major failure mode during earthquakes [1] [3]. For the pipeline under dynamic action, the calculation result of the inertia force of the pipe body and water is very close to the result of the static action. Because the inertia of the pipeline is very small [4] [6], it can ignore the dynamic effect, and directly consider the pipeline stress under the static load.

The model simplifies the seismic wave into sine wave, which is easy to be calculated, but in accordance with seismic thinking. So the relevant norms of the United States and China's Code for seismic design of outdoor water supply and gas and thermal power engineering GB50032-2003 [7] are using this method.

\section{A. Basic Assumptions}

1) The propagation of seismic wave in soil is idealized as a sine wave, as shown in the following figure 1: 


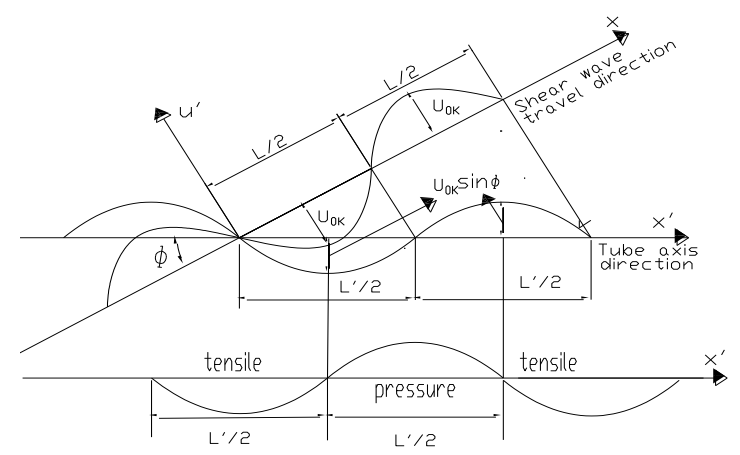

Figure 1. Effects of seismic ware on buried pipelines

$$
\mathrm{u}=u_{0 k} \sin \frac{2 \pi x}{L}
$$

Where, $\mathrm{u}$ is the displacement of soil along the wave propagation direction, $\mathrm{L}$ is the wavelength, $\mathrm{x}$ is the axial displacement of the wave and $\mathrm{u}_{0 \mathrm{k}}$ is the amplitude. The angle between the direction of the incident wave and the tube axis is $\phi$. Vertical decomposition of the seismic wave, then the soil vertical displacement can be expressed as

$$
u_{y}=u \cos \phi=u_{0 k} \cos \phi \sin \frac{2 \pi x}{L}
$$

2) For the water in the pipeline, it is assumed that the water is a constant flow, incompressible, non viscous:

This assumption implies that the water in the pipe can be solved according to the correlation equation of the onedimensional pipe flow in hydraulics.

3) The soil is regarded as elastic material, and the plastic deformation of the soil is neglected:

According to this assumption, can be regarded as soil and earth between the soil spring link.

B. Vertical Force Balance Equation of Pipeline Unit 2.

Vertical stress model of pipeline unit: as shown in figure

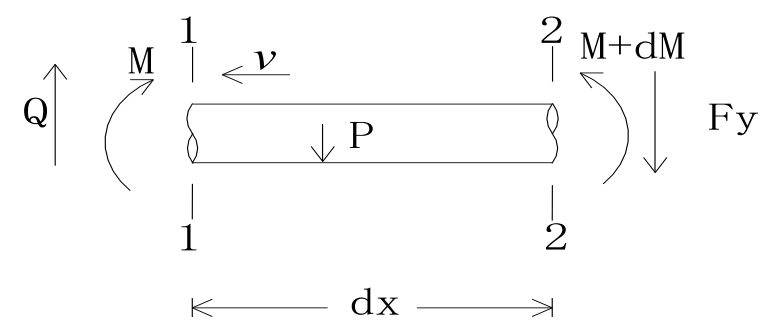

Figure 2. Model of pipe element on the vertical motion

Figure: $\mathrm{dx}$ for the length of the pipe unit, the section bending moment is $\mathrm{M}$, pipe bending deformation $u_{y g}, \mathrm{Q}$ for pipe shear, $\mathrm{V}$ is the speed of the water flow in the pipeline, $\mathrm{P}$ for water pressure on the inner wall of the pipelines, Fy for soil spring force on the pipeline.

1) Force of water to pipeline:

According to the fluid energy conservation equation [10]

$$
Z_{1}+\frac{p_{1}}{\eta}+\frac{v_{1}^{2}}{2 g}=Z_{2}+\frac{p_{2}}{y}+\frac{v_{2}^{2}}{2 g}+h_{f}
$$

Where, $Z_{1}, Z_{2}$ respectively for the $1-1$ section and 2-2

$$
\underline{p_{1}}, \underline{p_{2}}
$$

section of the position of head; $\gamma \gamma$ respectively for the 1-1 section and the 2-2 section of the pressure head; $\frac{\nu_{1}^{2}}{2 g}, \frac{\nu_{2}^{2}}{2 g}$ respectively for 1-1 section and 2-2 section of the velocity head; ${ }^{h}$ for the head loss along the way, referred to

$$
H_{1}=H_{2}+h_{f}
$$

Assuming the pipeline level and the velocity is constant, there is $Z_{1}=Z_{2} ; \frac{v_{1}^{2}}{2 g}=\frac{v_{2}^{2}}{2 g}$.

Balance equation can be simplified as

$$
\frac{p_{1}}{z}=\frac{p_{2}}{7}+h_{f}
$$

In the dynamic case, the inertia effect of the pipeline is very small, that is, the inertia force of the water is very close to that of the static state. The hydrostatic pressure of the water to the pipe wall is

$$
\begin{gathered}
\mathrm{P}=\not H d \\
\mathrm{H}=H_{1}-H_{2}=h_{f}
\end{gathered}
$$

So there

$$
\mathrm{P}=\not h_{f} d
$$

$$
h_{f}=\frac{2 v^{2}}{2 g d} \mathrm{dx}
$$

The vertical pressure of the water to the pipe is

$$
\mathrm{P}=\sqrt{2 v^{2}} \frac{2 v^{2}}{2 g d} d \mathrm{dx}
$$


2) Vertical force balance equation of pipeline unit:

The vertical force balance equation of the pipeline unit is

$$
F_{y}+P=Q
$$

The relationship between deformation and bending moment of pipe is

$$
\mathrm{M}=-\mathrm{EI} u_{y g}{ }^{\prime \prime}
$$

Type, $\mathrm{M}$ is the moment that the pipeline is subjected to; $\mathrm{I}$ is the moment of inertia of the cross section of the pipeline;

$u_{y g}$ the vertical displacement of the pipeline.

According to the basic differential relations of material mechanics,

$$
\begin{gathered}
\frac{d^{2} M}{d x^{2}}=Q=\mathrm{EI} u_{y g}{ }^{(4)} \\
F_{y}=K_{y}\left(u_{y}-u_{y g}\right)
\end{gathered}
$$

In the formula, $\mathrm{Q}$ is the shear force that the pipeline is subjected to, and $\mathrm{Ky}$ is the coefficient of the vertical soil spring for the pipeline unit.

The equilibrium equation of the pipeline is obtained.

$$
\begin{gathered}
K_{y}\left(u_{y}-u_{y g}\right)+\frac{\partial 2 v^{2}}{2 g} \mathrm{dx}=\mathrm{EI} u_{y g}{ }^{(4)} \\
\frac{\delta^{5} v_{g}}{\partial x^{5}}+\frac{K_{y}}{E I}\left(u_{y}-u_{y g}\right)-\frac{\partial 2 v^{2}}{2 g E I}=0
\end{gathered}
$$

Transfer coefficient of soil vertical displacement [8]

$$
\eta_{y}=\frac{1}{1+\frac{E x}{R_{y}}\left(\frac{2 \operatorname{mov} x^{2}}{L}\right)^{4}}
$$

When $\Phi=0^{\circ}$, the displacement transfer coefficient is maximum, then

$$
\begin{gathered}
\eta_{y}=\frac{1}{1+\frac{E E}{K_{y}}\left(\frac{25}{L}\right)^{4}} \\
v_{g}=\eta_{y} v=\frac{1}{1+\frac{E v}{K_{y}}\left(\frac{2 g}{L}\right)^{4}} u_{0 k} \cos \phi \sin \frac{2 \pi x}{L}
\end{gathered}
$$

$\mathrm{M}=-\mathrm{EI} v_{g}{ }^{\mathrm{N}}=\left[\frac{1}{\operatorname{EI}\left(\frac{2 \pi}{L}\right)^{2}}+\frac{1}{K_{y}}\left(\frac{2 \pi}{L}\right)^{2}\right]^{-1} u_{0 k} \cos \phi \sin \frac{2 \pi x}{L}$

3) Vertical stress of pipe unit:

Vertical stress suffered by the pipeline

$$
\sigma_{y}=\frac{M}{W_{z}}+\frac{p}{S}
$$

In the formula, it is the bending section coefficient. For a pipeline

$$
\begin{gathered}
W_{Z}=\frac{\pi\left(D^{4}-a^{4}\right)}{32 D} \\
\frac{M}{W_{Z}}=\left[\frac{1}{E I\left(\frac{2 \pi}{L}\right)^{2}}+\frac{1}{K_{y}}\left(\frac{2 \pi}{L}\right)^{2}\right]^{-1}\left[\frac{\pi\left(D^{4}-a^{4}\right)}{32 D}\right]^{-1} u_{0 k} \cos \phi \sin \frac{2 \pi x}{L}
\end{gathered}
$$

$$
\frac{P}{s}=\frac{\frac{d v^{2}}{2 g} \mathrm{dx}}{\operatorname{sudx}}=\frac{2 y v^{2}}{2 \pi g d}
$$

(22), (23) into the formula (21) is

$$
\sigma_{y}^{\prime}=\left[\frac{1}{E I\left(\frac{25}{L}\right)^{2}}+\frac{1}{K_{y}}\left(\frac{2 \pi}{L}\right)^{2}\right]^{-1}\left[\frac{\pi\left(D^{4}-a^{4}\right)}{32 D}\right]^{-1} u_{0 k} \cos \phi \sin \frac{2 \pi x}{L}+\frac{2 y v^{2}}{2 \pi g d}
$$

\section{PARAMETER DETERMINATION}

\section{A. Determination of Seismic Wave Amplitude}

According to the literature, the amplitude of the seismic wave can be determined by the following equation [7]

$$
u_{0 k}=\frac{\operatorname{\alpha g} I_{g}^{\circ}}{4 \pi^{2}}
$$

Where, $\alpha$ is the horizontal seismic influence coefficient; $\mathrm{Tg}$ is the characteristic period of the site soil, depending on the nature of the area and soil.

\section{B. Determination of the Coefficient of Vertical Soil Springs}

Method for reference of the value method of vertical soil spring coefficient, Code for seismic design of buried steel pipeline in oil (gas) transportation [9] 


$$
K_{y}=3 G^{\prime}=3 \frac{\gamma g}{g} V_{s}^{2}
$$

In the formula, $\mathrm{G}^{\prime}$ is the soil shear modulus; $\gamma^{\prime}$ is soil bulk density; $g$ is the acceleration of gravity; ${ }^{V_{s}}$ is the seismic shear wave velocity.

C. Determination of the Drag Coefficient along the Road

According to the Nikuradse formula

$$
\lambda=\frac{1}{\left[21 \operatorname{gg}\left(3.7 \frac{d}{4}\right)\right]^{2}}
$$

Where, $\Delta$ is the equivalent roughness of the pipe. The equivalent roughness of various wall materials is shown in Table I [10].

TABLE I. The Equivalent Roughness of Some Kinds of PiPES

\begin{tabular}{|c|c|}
\hline Tube wall material & $\Delta(\mathrm{mm})$ \\
\hline PE, aluminum & $0.0015 \sim 0.015$ \\
\hline Welded steel pipe & 0.046 \\
\hline Steel, paint & 0.06 \\
\hline cast iron & $0.3 \sim 1.0$ \\
\hline Cast iron, asphalt coating & $0.12 \sim 1.0$ \\
\hline Iron, paint & 0.15 \\
\hline Cast iron, rust & $1.0 \sim 1.5$ \\
\hline Iron deposit & $1.5 \sim 3.0$ \\
\hline
\end{tabular}

IV. EXAMPLE ANALYSIS

TABLE II. DIAMETER CONTROL TABLE

\begin{tabular}{|l|l|l|}
\hline \multicolumn{1}{|c|}{ Pipe diameter } & $\begin{array}{c}\text { Outside diameter of } \\
\text { pipe } \\
\mathbf{D}(\mathbf{m m})\end{array}$ & \multicolumn{1}{|c|}{$\begin{array}{c}\text { Pipe internal } \\
\text { diameter } \\
\boldsymbol{D}(\mathbf{m m})\end{array}$} \\
\hline DN100 & 118 & 100 \\
\hline DN200 & 222 & 203.4 \\
\hline DN400 & 429 & 402.8 \\
\hline DN500 & 532 & 504 \\
\hline DN600 & 635 & 605.2 \\
\hline DN800 & 842 & 806.6 \\
\hline DN1000 & 1048 & 1009 \\
\hline
\end{tabular}

TABLE III. DIFFERENT SHEAR WAVE VELOCITY AND CHARACTERISTIC CYClE OF DiFFERENT

\begin{tabular}{|l|l|l|}
\hline Soil type & \multicolumn{1}{|c|}{$\begin{array}{c}\text { Shear wave } \\
\text { velocity }(\mathrm{m} / \mathrm{s})\end{array}$} & $\begin{array}{c}\text { Characteristic period } \\
(\mathbf{s})\end{array}$ \\
\hline I type soil & 600 & 0.25 \\
\hline II type soil & 300 & 0.35 \\
\hline IIItype soil & 200 & 0.45 \\
\hline IVtype soil & 100 & 0.65 \\
\hline
\end{tabular}

TABLE IV. MAXIMUM VALUE OF HORIZONTAL EARTHQUAKE INFLUENCE COEFFICIENT

\begin{tabular}{|c|l|l|l|l|}
\hline $\begin{array}{c}\text { earthquake } \\
\text { intensity }\end{array}$ & 6 degrees & 7 degrees & 8 degrees & 9 degrees \\
\hline$\alpha$ & 0.04 & 0.12 & 0.24 & 0.32 \\
\hline
\end{tabular}

TABLE V. PARAMETER CONTROL TABLE

\begin{tabular}{|c|c|c|c|}
\hline $\begin{array}{c}\text { Elastic } \\
\text { modulu } \\
E(\mathrm{~N} / \mathrm{mm} 2)\end{array}$ & $\begin{array}{c}\text { Incident angle } \\
\text { of seismic } \\
\text { wave } \phi\left(^{\circ}\right)\end{array}$ & $\begin{array}{c}\text { Equivalent } \\
\text { roughness of } \\
\text { pipe } \\
\Delta(\mathrm{mm})\end{array}$ & $\begin{array}{c}\text { Soil bulk } \\
\text { density } \\
\gamma(\mathrm{N} / \mathrm{m} 3)\end{array}$ \\
\hline $1.6 \times 10^{\wedge} 5$ & 45 & 0.7 & $3 \times 10^{\wedge}(-3)$ \\
\hline
\end{tabular}

In this paper, the cast iron pipe produced by Xinxing Ductile Iron Pipe Co., Ltd is taken as an example to calculate the vertical force of the pipe considering water and not considering the water pipe, considering the effect of water velocity on the pipeline's stress, and the stress of pipelines varies with seismic intensity, soil quality and pipe diameter in both cases. The inner and outer diameters of each pipe are shown in Table II, and the other parameters are shown in Table III, Table IV, and Table V.

\section{A. Numerical Example 1}

Assuming that the pipe is in the third category of soil, the vertical force of the pipe is calculated as $v=0.8 \mathrm{~m} / \mathrm{s}, \mathrm{v}=1 \mathrm{~m} / \mathrm{s}$, $\mathrm{v}=1.2 \mathrm{~m} / \mathrm{s}$ and there is no water in the pipe when seismic intensity changing.

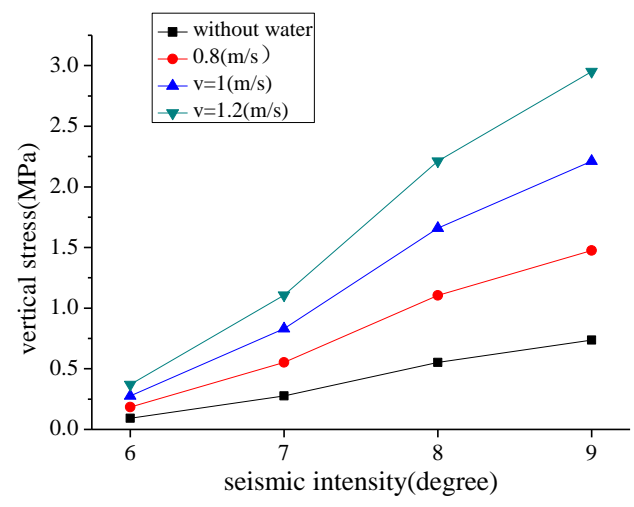

Figure 3. Relationship between vertical stress and seismic intensity of pipeline DN100 


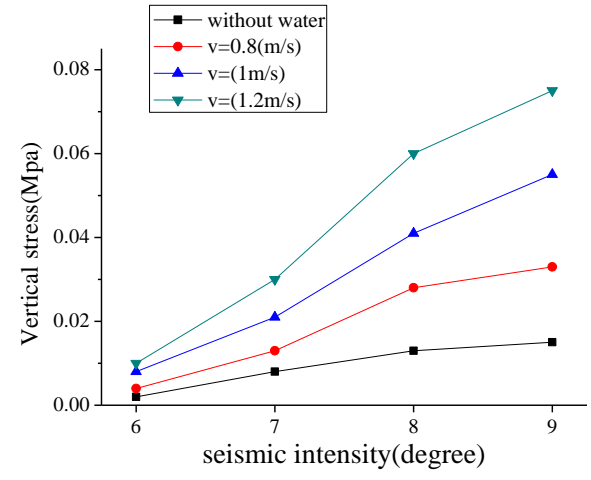

Figure 4. Relationship between vertical stress and seismic intensity of pipeline DN500

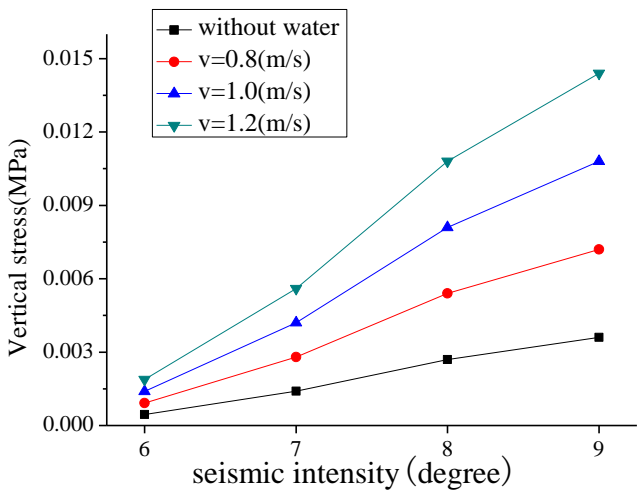

Figure 5. Relationship between vertical stress and seismic intensity of pipeline DN1000

Figure 3-5 shows: The greater the seismic intensity, the greater the vertical force of the pipeline; When the pipeline filled with water, the vertical force is greater than no water; With the increase of flow velocity, the vertical force of pipeline is more and more; The higher the flow velocity, the more obviously the vertical force of the pipeline changes with the increasing of seismic intensity; The greater the seismic intensity, the greater the influence of the flow velocity on the vertical force of the pipeline.

\section{B. Example 2}

Earthquake intensity is 8 degrees, and the vertical force of the pipeline filled water and without water, which changes with the site soil type, is calculated when the water velocity is $\mathrm{v}=0.8 \mathrm{~m} / \mathrm{s}, \mathrm{v}=1 \mathrm{~m} / \mathrm{s}, \mathrm{v}=1.2 \mathrm{~m} / \mathrm{s}$ respectively. Diameter DN100, DN500, DN1000, pipe vertical force results as shown below

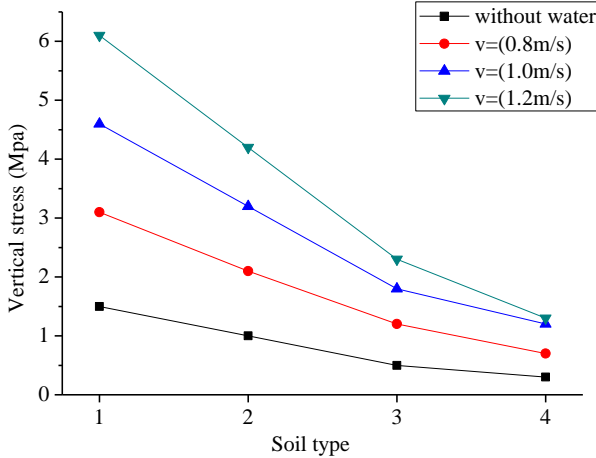

Figure 6. The relationship between vertical stress and soil type of DN100 pipeline

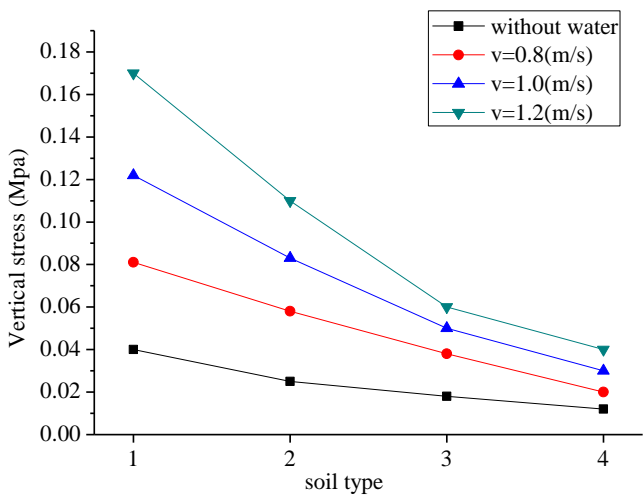

Figure 7. The relationship between vertical stress and soil type of DN500 pipeline

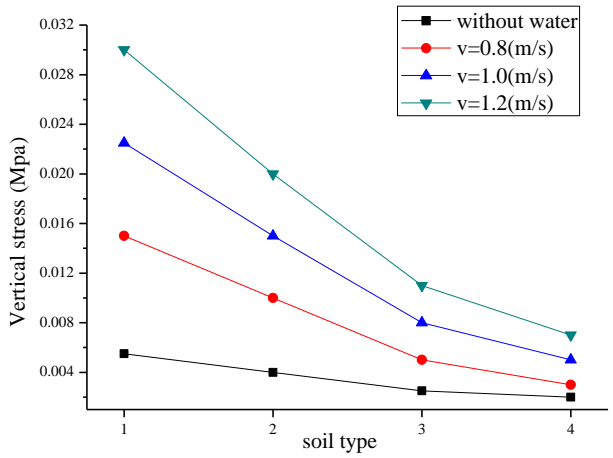

Figure 8. The relationship between vertical stress and soil type of DN1000 pipeline

Figure 6-8 shows: The more soft the soil of the site, the smaller the vertical force pipeline; When the pipeline filled with water, the vertical force was greater than no water; With the increase of flow velocity, the vertical force of pipeline is more and more. The higher the flow velocity, the more obvious the vertical force of the pipeline decreases with the 
soil softening. With the softening of the soil, the impact of the pipe flow velocity on the pipeline is less obvious.

\section{Example 3}

Assuming that the soil type of the site is the third category of soil, the seismic intensity is 8 degrees. The vertical force of the pipeline filled water and without water, which changes with the diameters, is calculated when the water velocity is $\mathrm{v}=0.8 \mathrm{~m} / \mathrm{s}, \mathrm{v}=1 \mathrm{~m} / \mathrm{s}, \mathrm{v}=1.2 \mathrm{~m} / \mathrm{s}$ respectively. The results are shown in Figure 9.

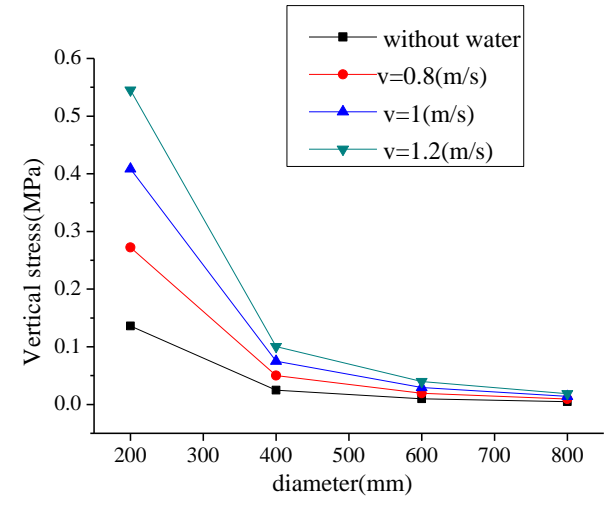

Figure 9. The curve of pipeline vertical stress and pipe diameter

Figure 9 shows: The smaller the diameter, the greater the vertical force of the pipeline. With the diameter of the pipeline smaller, the force becomes small and tends to be stable; when the pipeline filled with water, the vertical force was greater than no water; with the increase of flow velocity, the vertical force of pipeline is more and more. The larger the flow velocity is, the more the vertical force decreases with the increase of pipe diameter. When the pipe diameter increases to a certain value, the effect of flow velocity on the pipeline will be obviously smaller.

\section{CONCLUSIONS AND RECOMMENDATIONS}

\section{A. Conclusions}

(1) On the basis of elastic foundation model and wave theory, considering the influence of water velocity on pipe, combined with the basic theory of fluid mechanics, the longitudinal stress of buried water supply pipe filled water is anslyzed in the state of bending stress. The equilibrium equation and the analytical solution of the stress of the pipe are obtained by derivation.

(2) By the force balance equation stress analysis model to be drawn:

- The greater the seismic intensity, the greater the vertical stress of the pipeline.

- With the increase of the flow velocity, the vertical stress of pipeline is more and more.
- The smaller the diameter, the greater the vertical stress pipeline, otherwise the opposite.

(3) When the pipeline is filled with water, the vertical stress of the pipeline is obviously higher than without water.

(4) The influence of flow velocity on the vertical stress of the pipe increases with the increase of the seismic intensity, the increase of the hardness of the soil and the decrease of the pipe diameter, and conversely, the opposite. The flow velocity has little effect on the longitudinal stress of the pipeline when seismic intensity relatively small, soft soil, and large diameter.

\section{B. Prospect}

The calculation model has a certain theoretical significance to the design of water supply pipe network and the seismic reliability of water supply pipe network and can be used to optimize the design of pipe network combined with the economic performance of water supply pipe network. The stress model has a certain reference value for the design of other pressure flow pipelines.

\section{ACKNOWLEDGMENT}

The supports from Hebei Provincial Department of Education Research Project (Fund No.Z2013099) and Hebei Province Postdoctoral Fund Project (Fund No .B2013005003) are greatly appreciated.

\section{REFERENCE}

[1] Kachadoorian, R, "Earthquake: Correlation between pipeline damage and geologic envirronment," Journal of AWWA, March 1976, pp.165167.

[2] Katayama. T, Kubo.K. and Sato. N, "Earthquake damage to water and gas distribution systems," Proc. of U.S. National Conference on Earthquake Engineering Ann Arbor, MI, eeri, 1975, pp. 396-405.

[3] King. P.V. and Betz. J. M, "Earthquake damage to a sewer system," Journal of Water Pollution Control Federation, May 1972, pp.859-867.

[4] Kubo.K, "Behavior of underground waterpipes during an earthquake," Porc, of 5th World Conference on Earthquake Engineering, IAEE, Rome, 1974, pp. 569-578.

[5] Okamoto. S. and Tamura. C, "Behavior of subaqueous tunnel during earthquakes," Lnt. Journ. of Earthquake Engr. and Struct. Dynamics, Vol. 1. No.3, Jan-Mar. 1973, pp. 253-266.

[6] Sakurai.A and Takahashi. T, " Dynamic stresses of underground pipelines during earthquakes," Porc, of 4th World Conference on Earthquake Engineering.

[7] Ministry of Housing and Urban-Rural Development of the People's Republic of China. Code for seismic design of outdoor water supply and gas and thermal power engineering [S]. 2003.

[8] Huang, Q. B. and Peng, J.B (2004) Seismic Response Analysis of Buried Pipeline under Seismic Wave. Engineering Survey. 64-67.

[9] National Development and Reform Commission, Code for Seismic Design of Buried Steel Pipeline for Oil Transportation (Gas) [S]. 1991.

[10] Yu, B. and Yin, X.L, Hydraulics [M]. Second Edition. Guangzhou: South China University of Technology Press, 2007: 134-135. 